\title{
«ПАТРИОТИЗМ ЭЛИТ» КАК ДИСКУРСИВНОЕ ИЗМЕРЕНИЕ СИМВОЛИЧЕСКИХ СТРУКТУР НАЦИОНАЛЬНОЙ ПАМЯТИ ${ }^{1}$
}

\author{
К.Ф. Завершинский
}

\author{
(zavershinskiy200@mail.ru) \\ Санкт-Петербургский государственный университет, \\ Санкт-Петербург, Россия
}

Цитирование: Завершинский К.Ф. «Патриотизм элит» как дискурсивное измерение символических структур национальной памяти // Власть и элиты. 2020. T. 7, № 2. С. 77-96.

DOI: https://doi.org/10.31119/pe.2020.7.2.4

Моральная интеграция общества и коллективная идентичность на основе кодекса патриотизма преодолела региональные и иерархические различия; такая идентичность, казалось бы, разрывающая связь с естественными и личностными корнями, основанная на представлении об анонимной общественности, подготовила возникновение идеи современного общества, где взаимосвязь индивидов осуществляется на основе соотнесенности с идеями равенства, морали и гражданских добродетелей [Eisenstaedt, Giesen 1995: 87-88].

Аннотация. Рассматривается значение исследования места и роли дискурса патриотизма для процесса политической идентификации современных элит. Автор полагает, ито доминирование ценностно-нормативных и позитивистских исследовательских стратегий при изучении политических коммуникаций элит только частично отражает качественные изменения в процессах их политической идентификации. Более перспективными являются исследовательские стратегии современной культурсоциологии политических феноменов, которые позволяют интерпретировать мобильность политической идентификаиии элит с позииий динамики символических структур национальной памяти. Ис-

${ }^{1}$ Исследование выполнено при финансовой поддержке РФФИ и ЭИСИ в рамках научного проекта № 20-011-31690/20. 
следование влияния символических структур национальной памяти на процесс политической идентификаиии элит позволяет более адекватно выявить роль дискурса патриотизма в соииальном конструировании пространства политической солидарности в современных начиональных сообществах. Важную роль в исследовании политической идентификации элит играет изучение влияния профилей тегитимации национальной памяти на специфику их патриотической/непатриотической идентибикаици, позволяющее учитьвать специфику конкуренции символических репрезентаций образов прочлого и будущего, типологии герочческого, представлений о вине и ответственности элит. Используя теоретические посылки культурсоииологического анализа современной политической культуры как национальной памяти в качестве методологической основы, автор предлагает новый теоретический подход к изучению феномена «патриотизм элит».

Ключевые слова: политические элиты, политическая коммуникаиия, национальная память, политическая солидарность, дискурс патриотизма.

\section{ВВЕДЕНИЕ}

Актуальность обращения к исследованию места и роли дискурса патриотизма в социокультурной динамике политической идентификации элит в символическом пространстве современной национальной памяти обусловлена растущей фрагментацией геополитического порядка и резким возрастанием амбивалентного влияния культурных, символических ресурсов на институциональную и организационную динамику властных элит. В этом контексте односторонним выглядит описание политической идентификации политических элит исключительно как результата их институциональной и организационной динамики, практик целеполагания в процессе их внутри- и внешнеполитического позиционирования, внутриэлитного или межэлитного взаимодействия при принятии политических решений.

Значимость подобных теоретических посылок возрастает в реалиях современных политических коммуникаций, когда наблюдается углубление кризиса идентичности национальных и транснациональных элит. Прогнозы об отмирании мифологии национального государства, «европеизации» и «космополитизации элит», преодоления рисков «нового глобального класса» под эгидой США посредством «реалистического либерального космополитизма» [Бек 2008] не сбываются. Все очевиднее возрастание влияния популистских и имперских моделей идентифика- 
ции и архаизации практик политической консолидации элит на основе партикулярных кодексов солидаризации. Не исключение в этом отношении и коммуникативное пространство современной России. Авторитетные представители российской элитологии, анализируя направленность исследований феномена элиты и особенности ее политической идентичности, отмечают, что изменения в структуре российской элиты в последнее десятилетние свидетельствуют о переходе российской политической элиты от системы «разделения кланов» (суррогата разделения властей) к модели встроенности подобных кланов в вертикали власти и связанные с этим острые внутриэлитные конфликты [ГаманГолутвина 2016: 87-88]. В постперестроечной России использование элитами культурного капитала в процессе их легитимации и публичной самопрезентации все очевиднее приобретает политико-инструментальный характер, который в рамках современных либеральных представлений проявляется в индивидуальной автономизации политиков, возрастанию цинизма, беспардонности как принципа деятельности публичных акторов: персональной смене политической идентичности, перехода из одного лагеря в другой, релятивности морально-политического пространства, продуцировании безответственных перед людьми и страной делегитимирующих суждений [Дука 2018: 128-131].

Это актуализирует проблему возвращения и теоретической реконструкции патриотических кодексов идентификации национальных элит с учетом реалий современных политических коммуникаций, способных преодолеть рост насилия внутри национальных и больших политических пространств, выработку в перспективе контуров нового, более устойчивого политического порядка. В свое время именно «патриотизм привел к возникновению более сложной формы коллективной идентификации, преодолевающей ограниченность идентичности, основанной на сословной или региональной идентичности» [Eisenstaedt, Giesen 1995: 87]. Изучение места и роли дискурса патриотизма элит, его эволюции и инволюции в национальном и глобальном пространствах приобретает особую значимость в условиях нарастания неопределенности в социальном воспроизводстве экономических, политических и символических границ политических общностей. Актуализирует подобное исследование происходящая в современном мире смена и поколений элит, и их политико-культурной идентичности.

Актуальными в связи с этим выглядят теоретические ремарки Н. Лумана при описании процессов идентификации и социализации. 
Луман отмечал, что идентичности и их дискурсивные проекции «задумываются для связи ожиданий» [Луман 2007: 413], которые конституируются при их включенности в темпоральные символические структуры коммуникативных событий (социальной памяти), что обеспечивает устойчивость динамической репродукции комплекса подобных ожиданий. При исследовании политической социализации и идентификации элит важно учитывать, что это всегда «самосоциализация» в коммуникативном пространстве национальной памяти, а не просто поддержание или перенос ценностно-нормативных, идеологических моделей целеполагания. Политическую идентификацию элит как возникновение/разрушение смыслового единства (политического понимания) никогда нельзя целиком сводить к целеполаганию взаимодействующих, поскольку их действия, интересы и мотивы в процессе коммуникации обретают новое смысловое измерение. Идентифицируют и социализируют не действия, а их включенность в символические структуры событий, связывающих ожидания, что и порождает коммуникативное понимание/непонимание [Луман 2007: 319-321, 413].

В этом методологическом контексте значимой задачей специфики исследования дискурса патриотизма, видится разработка междисциплинарной методологии политико-культурных исследований в целях научного прогнозирования процесса политической идентификации и легитимации национального позиционирования политических элит современной России. Исследование этого процесса в семантическом и категориальном фокусе «национальной политической памяти» позволяет отвечать на вопрос, какие символические структуры определяют специфику дискурса патриотизма в том или ином национальном сообществе и каким образом многослойность дискурсов патриотизма «имеет значение» для действенной прагматики политической идентификации элит и легитимации национальных политических систем. Это позволяет теоретически и эмпирически операционализировать феномен патриотизма элит как комплекс символических репрезентаций и нарративов, возникающих в национальной памяти и связанных с социальным конструированием пространства политической солидарности.

Представленная работа нацелена на получение ответов на ряд вопросов, значимых, по мнению автора, для осмысления специфики процесса политической идентификации политических элит в реалиях современных политических коммуникаций. Какие символические структуры национальной памяти определяют динамику смысла и со- 
держания дискурсов патриотизма, характерных для национальных политических элит? Как формы политической солидарности, доминирующие в том или ином национальном сообществе, влияют на социальное конструирование патриотического дискурса элит, обусловливая жизненность тех или иных его дискурсивных вариаций в их практиках политической легитимации и самолегитимации. Наконец, чем обусловлен конфликт нарративов патриотизма в процессе идентификации российских политических элит?

\section{КОММУНИКАТИВНЫЕ ИЗМЕРЕНИЯ СОВРЕМЕННОЙ НАЦИОНАЛЬНОЙ ПАМЯТИ}

Не подвергая сомнению значимость и перспективность исследования политической идентификации элит в контексте их ценностно-нормативных ориентаций, следует заметить, что подобные исследования обращают внимание преимущественно на пространственные границы подобной идентификации, особенности символического позиционирования элит в политическом пространстве. В то время как темпоральные измерения этого процесса и его коммуникативная тематизация, связанная с социальным конструированием смысловых образцов политических ожиданий (от чего, собственно, зависит степень автономности и действенности позиционирования элит), часто остаются на периферии исследований. В современных коммуникативных реалиях актуализируются теоретические посылки социологии дискурсивных и символических измерений национальной идентичности, артикулированные в конце XX столетия и получившие свое развитие в современной культурсоциологии и антропологии политики, которые нацелены на изучение символических кодов и базовых нарративов национальной идентичности, обеспечивающих солидарное существование в комплексных обществах ${ }^{1}$.

Национальная идентичность, как и иные формы коллективной идентичности в комплексных обществах, нуждающихся в публичных сферах, возникает при социальном конструировании символических границ сообществ на основе символизации процессов «включения и исключения» «ожиданий других» из этого сообщества. Подобное раз-

${ }^{1}$ Более подробно о специфике и возможностях культурсоциологической эпистемологии исследования социокультурной динамики политических элит, ее пространственно-временных измерений см. в: [Завершинский 2018]. 
личение предполагает эволюцию и усложнение символических кодексов этого различения от примордиальных и сакральных к гражданским, которые возникают при пространственно-временном маркировании в комплексных обществах.

Анализ социального конструирования символических границ национальных сообществ предполагает выход за рамки трактовки политико-культурного процесса как социокультурной динамики ценностных или идеологических преференций политических субъектов. При социальном конструировании диалога между национальными элитами важно учитывать различия в понимании ими значимого прошлого, настоящего и будущего, характерных для этих сообщества, особенностей их коммуникативного «связывания» в символических структурах национальной памяти. Эта теоретико-методологическая установка позволяет переопределить концепты нации и национальной идентичности, выводя их за рамки субстанционалистских трактовок национального сообщества как носителя культуры, языка, религии, артикулировать глубинные основания культурной специфики пространственно-временных параметров национальной общности, связанных с символическими репрезентациями травматического опыта становления нации, выявить специфику патриотического дискурса.

У многих национальных общностей в современном мире существуют политические, экономические, социальные границы, но при этом очевидно нарастает неопределенность в символических границах, связанных с динамикой социальной памяти под влиянием современных коммуникаций. Если концепт «политическая культура» в традиционном социологическом и политологическом дискурсе позволяет наблюдать динамику ценностных ориентаций в пространстве социальной идентификации, то анализ феномена национальной идентичности в семантическом и категориальном фокусе «национальной памяти» позволяет отвечать на вопросы о том, как и каким образом многослойность рационализированных и эмоционально-чувственных репрезентаций коллективно-значимых представлений «имеет значение» для действенной прагматики национальной идентификации и легитимации национальных политических систем. Национальная память как историческая модификация политической памяти, обладающая по сравнению с предшествующими историческими формами большей темпоральной длительностью, сохраняет ведущую роль в легитимации социальных институтов и конструировании социально-политической преемственности 
[Ассман 2006: 210-226]. Процессы, происходящие в современной национальной памяти, все чаще являются решающими «символическими триггерами» процесса производства идентичностей, интересов и значений во времени, а не статическим отражением эволюции институциональных структур или ценностных преференций культурных и политических элит. Исследование символической динамики процесса социального конструирования и эволюции современной национальной идентичности в контексте коммуникативных процессов национальной памяти предполагает анализ темпоральных режимов и исторических форм, уровней национальной памяти [Ассман 2017], «прагматики» ее мнемонических процессов и продуцирования символических кодов публичного пространства и политической солидарности [Alexander 2006: 29-89].

Другим важным коммуникативным измерением национальной памяти является исследование «работы» национальной памяти по продуцированию и разрушению национальной идентичности и идентичности элит, изучение специфики ее «символических фигураций», отражающих меняющиеся отношения между прошлым и настоящим. Эти отношения обусловлены взаимосвязью процесса конфликтной борьбы «памятей», конкуренции жанров и профилей легитимации [Olick 2016: 36-76]. Описание профилей легитимации национальной памяти предполагает исследование конфликтной динамики символических контуров национальной памяти, включающей разнообразные конкурирующие смысловые компоненты (образы прошлого, политические характеристики элит, типологию героического, представления о долге, вине и ответственности, приоритетные стратегии и практики борьбы с «врагами»), определяющие характер возникновения и умножения конфликтов идентичностей.

Таким образом, социологическое моделирование процессов, происходящих в национальной памяти современных сообществ и связанных с этим элитных социально-политических конфликтов в политическом пространстве, могло бы содействовать артикуляция научного дискурса, ориентированного на понимании национальной идентичности элит как результата социокультурного структурирования символических компонентов национальной памяти. Методологический переход от анализа политической культуры как ценностно-нормативной структуры, зависимой от институциональных и организационных форм социума, к разработке моделей ее коммуникативной автономии и специфики позволяет сконцентрировать внимание на изучении пространственно- 
темпоральных структур ожиданий политической памяти, где специфика (конфигурация) пространственной и временной символизации публичного принуждения определяет социальное конструирование политических событий и форм политической солидарности.

\section{КОММУНИКАТИВНЫЕ ИЗМЕРЕНИЯ ПОЛИТИЧЕСКОЙ СОЛИДАРНОСТИ ЭЛИТ}

Политико-антропологическая специфика социальных форм солидарности определяет превращение коллективных представлений в нарративы, жизненно важные для создания и поддержания национальных идентичностей и разрешения конфликта между элитными группами. Принципиальным в рамках стратегии исследования динамики «программ политического опыта» (политической памяти) является изучение базовых культур - антропологических моделей форм политической солидарности, определяющих социокультурную специфику политических идентичностей. По нашему мнению, анализ базовых форм политической солидарности возможен на основе grid-group-анализа, предложенного в свое время М. Дуглас и адаптированного представителями культурной теории к политическим реалиям политики в национальных сообществах [Thompson 2005: 1-22]. Подобная исследовательская стратегия позволяет выделить модели социальной солидарности, а также дает возможность артикулировать многообразие их комбинаций, определяющих специфику и направленность политики памяти в современных реалиях взаимодействий национальных государств. Символические формы солидарности выступают своего рода интегралом взаимодействий на макроуровне и уровне повседневности.

Измерение по шкалам мировоззренческой сети представлений (grid) и групповых преференций (group), нормативных ограничений, связанных с принадлежностью к культурной общности и конкретной социальной группе, позволяет выявить специфику форм солидарности и их символического потенциала по преодолению рисков и опасностей конфликтной динамики внутренней и внешней среды существования современных политических общностей. Это дает возможность выделить «идеально-типические» модели социальной солидарности на пересечении мировоззренческой и групповой осей, которые могут быть использованы для характеристики своеобразия и влияния этих форм солидарности 
на социальные взаимодействия, в том числе политические, в которые вступают люди (индивидуализм, фатализм, иерархизм, эгалитаризм), и их комбинации. Отсюда следуют четыре базовых космологии и стратегии достижения целей, связанные с восприятием границ политического, национального суверенитета, демократии: восприятие политики как рачионально-управляемого и директивно-управляемого (политический индивидуализм и иерархизм) и как некой культурной антитезы индивидуализму и иерархизму - признание непредсказуемости политических коммуникаций (политическиц̆ батализм) и мировоззренчески диффузная политика эгалитаризма.

Наблюдение в пространстве этих двух осей измерения и четырех «идеально-типических» конструкций солидарности позволяет артикулировать многообразие их комбинаций, определяющих специфику способов обоснования политических идентичностей в современных реалиях взаимодействий национальных государств. Соответственно эти формы солидарности отличаются способами интерпретации смысла политического и способах легитимации политического порядка, стратегиями реализации политическими элитами внутренней и внешней политики, режимами политического времени, стратегиями реализации политического суверенитета и степени нормативных ограничений, которые признают члены солидарных сообществ. Наличие мифического ядра, неотъемлемого элемента любой космологии политической солидарности, проявляется в презентации коллективной, взаимной ответственности за действия в чувственно-образной символической форме. Именно антропологическая специфика форм солидарности определяет превращение коллективных представлений в нарратив, жизненно важные для создания и поддержания национальных идентичностей и конфликта между ними. Примером может служить современная конфронтация политических элит (войн памяти), обусловленная, например, противостоянием нарратива и мифологии евроатлантической солидарности по отношению к другим, качественно отличным нарративам национальной солидарности, связанным с различиями в понимании и интерпретации учреждающих политических событий, образцов героического и представлений о долге, вине, ответственности и приоритетных стратегий политики памяти, реализуемых элитами. В этом контексте политическая элита России существует в рамках слабой системы культурных классификаций и достаточно сильной зависимости от групповой принадлежности 
и неэффективной директивно-управляемой вертикали. Предпосылки политической конфронтации российских политических элит связаны с доминированием у них эклектики стратегий «безответственного» индивидуализма, иерархизма или эгалитаризма.

Зависимость принимаемых элитами решений от символических структур солидарности или попытки радикального их переформатирования в процессе проводимой современными элитами политики памяти стимулируют как появление пространств символической комплементарности, так и конфронтацию идентификационных символических кодов. Активизация маргинальных нарративов в символических структурах политической памяти ведет к легитимации насильственных стратегий и поведенческих моделей по отношению к «иным» или «другим» формам солидарного существования.

\section{КОММУНИКАТИВНЫЕ ИЗМЕРЕНИЯ ДИСКУРСА ПАТРИОТИЗМА СОВРЕМЕННЫХ РОССИЙСКИХ ЭЛИТ}

В современных исследованиях дискурса патриотизма, на наш взгляд, можно проследить доминирование ценностно-нормативного измерения при интерпретации специфики его проявления в позиционировании политических элит. Несмотря на видимую вариативность подобных интерпретаций, все они так или иначе разделяют посыл о том, что качество патриотических убеждений связано со спецификой и интенсивностью процесса политической социализации, обусловленной политической преемственностью отношений между поколениями и ответственностью за этот процесс политических и культурных элит, призванных отыскать идеальные, духовные и сакральные основания патриотического поведения. Так, в современном отечественном академическом дискурсе при трактовке смысла и содержания феномена патриотизма доминирует трактовка патриотизма как специфической ценностной установки политического сознания, влияющей «на общественные отношения и деятельность, связанные с поддержкой и защитой гражданином политических институтов, отражающих его интересы» [Мартынов, Фадеева, Габеркорн 2020: 109-121]. Можно согласиться с важностью подобного измерения феномена патриотизма, поскольку система символических отображений и ритуалов патриотического поведения обеспечивает дополнительный уровень легитимации властных отношений. Семантическая последовательность в использовании элитами слов 
и символов при поддержании устойчивых образцов гражданского патриотизма расширяет возможности для политического консенсуса в ходе публичных дискуссий и устанавливает границы того, что относится к сфере асоциального, непатриотического взаимодействия.

При этом современные ценностно-нормативные трактовки содержания дискурса патриотизма в национальном пространстве современной России так или иначе отталкиваются от тех дискурсивных линий, которые начинают в XIX в. прослеживаться в социокультурном пространстве России. Это связано с тем, что происходит вызревание в рамках имперской теологической легитимации новых культурных проектов национальной идентичности, когда у властной элиты и новых социальных групп возникает потребность в идеологических, т.е. пригодных для инструментального использования, политических дискурсов, способных обеспечить более высокий уровень социального консенсуса в реалиях неизбежной модернизации российского общества. Показательно, что именно в этот период происходит закрепление и распространение в публичном пространстве понятия «патриотизм». Такими речевыми и символическими практиками, претендующими на роль дискурсов патриотизма, можно считать специфические российские версии консервативных, социалистических и либеральных ценностных установок. На рубеже XIX-XX вв. «качество» и оценка значимости дискурса патриотизма отчетливо колеблется в семантической бинарности признания нравственной ограниченности патриотизма до поисков «настоящего национализма», основанного на любви к «народному мы», скрепленному государственным правосознанием. Война семантики альтернативных дискурсов патриотизма в XX столетии завершилась доминированием идеологемы коммунистического интернационализма, постепенно трансформировавшейся в дискурсивную практику «социалистического отечества», сменившихся в период «перестройки» поисками либеральной версии «критического патриотизма». На настоящей фазе политической эволюции России прослеживается становление консервативных дискурсивных семантик, акцентирующихся на приоритете любви к «народному мы» при главенстве идеи сильного, авторитарного национального государства. Несмотря на перманентную артикуляцию в отечественном социально-политическом дискурсе дебатов о содержании и коммуникативных функциях феноменов «нового национализма» и патриотизма, патриотизма/антипатриотизма, национализма/космополитизма элит, их семантика достаточно часто редуциру- 
ется к частным дискурсивным измерениям, сопровождаемым идеологически аксиологизированной риторикой.

Несмотря на значимость современных исследований, специфики содержания российских патриотических убеждений в контексте ценностно-нормативной аксиоматики российской социально-философской и идеологической мысли о приоритете «либерально-демократических», «консервативных», «этнонационалистических», социалистических ценностных ориентаций, а также через призму прагматических «узусов» дискурса патриотизма в современных российских и западных массмедиа, сохраняется насущная потребность в разработке междисциплинарных социологических моделей социокультурной динамики нарратива патриотизма. Ценностно-нормативная аксиоматика дискурса патриотизма - важное, но всего лишь одно из измерений больших политических нарративов, связанных с процессом политической идентификацией национальных сообществ. Именно нарративы, в отличие от аксиологической семантики бинарного кодирования, привносят упорядоченность в представления о последовательности политических событий, позволяя ответить на вопросы «кто мы» и «откуда», согласовывая наши коллективные действия с «конечными» вопросам на уровне повседневности. Ценностный дискурс патриотизма всегда существует в пространстве и времени коллективно-значимых представлений о политике («политической памяти»), а не только как идеологический или пропагандистский эффект активности элит.

Современные политологические исследования феномена патриотизма в современном российском обществе нуждаются в новых политико-социологических измерениях, позволяющих вывести их проблематику на анализ действенности многоуровневых политических репрезентаций дискурса патриотизма. В связи с чем, по мнению автора, актуализируются теоретические посылки исторической социологии и современной культурсоциологии, ориентирующих на исследование исторической динамики внутриполитического и внешнеполитического позиционирования национальных сообществ в связи с символической спецификой пространственного и временного кодирования границ национальной памяти. Принципиальными в связи с этим видятся теоретические посылки Ш. Эйзенштадта и Б. Гизена, которые полагали, что при исследовании исторической динамики внутригруппового и внешнего позиционирования национальных сообществ, наряду с такими измерениями, как социальная дифференциация, контроль над распре- 
делением ценностей и институционализация, важно учитывать символическую специфику пространственного и временного кодирования границ подобных сообществ [Eisenstaedt, Giesen 1995: 72-102; Eisenstaedt 2002: 3-12].

При этом базовым доминирующим символическим кодом национальной идентичности является «гражданский код», репрезентируемый в патриотическом кодексе поведения, обеспечивающий более высокую по сравнению с предшествующими кодами (примордиальными и теологическими) уровень социальной идентификации и солидарного существования, преодолевающую сословные, этнические и региональные различия. Подобная политико-культурная динамика сопровождается конфликтной борьбой политических нарративов, конкуренцией жанров и профилей легитимации. Описание профилей легитимации национальной памяти предполагает исследование конфликтной динамики символических контуров национальной памяти, включающей разнообразные конкурирующие смысловые компоненты (образы прошлого, политические характеристики элит, типологию героического, представления о долге, вине и ответственности, приоритетные стратегии и практики борьбы с «врагами»), определяющие характер возникновения и умножения конфликтов идентичностей и специфику патриотических дискурсов.

Интерес представляет и методологическая позиция Б. Гизена, который полагает, что социологический взгляд на коммуникативную динамику социальной жизни, особенно на современную, должен быть существенно скорректирован в контексте модели «асинхронности» («разновременности»). Эта парадигма, по его мнению, способна преодолеть инерцию модернистской модели, рассматривающей общество как систему взаимосвязанных подсистем, которые в идеале должны быть плотно соединены друг с другом (обмениваться информацией точно и вовремя) и последовательно преодолевать несовершенство прошлого и сбои в координации систем [Giesen 2004: 27-40]. Социальная жизнь в контексте подобной исследовательской установки не работает согласно функционалистскому и прогрессистскому сценарию. Важно учитывать асинхронность («разновременность») различий в восприятии социального времени поколениями и связанную с этим значимость для них тех или иных социальных событий и способность людей к взаимной адаптации. Именно подобная «разновременность» ведет к тому, что новые поколения политических элит могут рассматривать инсти- 
туциональные нормы и образцы предыдущего как «устаревшие», нуждающиеся в радикальных преобразованиях. В стремлении сохранить поступательность в эволюции социальных институтов и культурных образцов из прошлого в настоящем элиты часто сталкиваются с групповыми различиями в своих временных горизонтах, восприятии значимости ключевых событий прошлого. То, что одно поколение элит помнит как победу, для другого поколения или группы людей, живущих в отличном горизонте времени, может восприниматься поражением или малозначимым событием. Экстраординарные политические события в жизни поколения элит, как, например, последствия военно-политических конфликтов, переворотов, пандемии, могут стремительно вывести их из «тени» политического опыта предшествующих поколений и принудить действовать самостоятельно, стимулировать действия по радикальному переформатированию существующих культурных образцов и институтов.

Смена политических элит предполагает, что они могут быть ориентированы на собственные значимые для них «события», значимые для их «успешного» существования в настоящем и будущем. Разрушение социума или гуманитарные катастрофы могут происходить относительно «скрыто» для многих групп, не вовлеченных непосредственно в этот процесс, объективные свидетельства о таких событиях могут быть уничтожены и никак не сказываться на национальной идентичности и идентичности властных элит, а эрозия символических границ национальной памяти, порожденная, например, символической политикой маргинальных элит и элитных групп, могут привести к эрозии и разрушению границ понимания и солидарных форм внутри социума, к утрате социального порядка, разрушению политических институтов и разрушению механизма поддержания политико-культурных санкций. Политическая «фактичность» принимаемых элитами политических решений обретает статус политических событий, входит в «опыт» (память нации и элит), когда она обретает статус коммуникативной драматургии. Не существует универсальных нормативных характеристик дискурса патриотизма, а поэтому репрезентация патриотизма в деятельности политических элит связана с особенностями пространственных и темпоральных границ политических коммуникаций и форм солидарности, характерных для тех или иных сообществ на конкретном этапе их политической эволюции. Политические дискурсы патриотизма элит всегда включены в социальные, культурные, экономические, политиче- 
ские и правовые коммуникации и связаны с вариативными контекстами времени.

В национальной памяти современной России прослеживается процесс конфликтной борьбы «памятей», столкновение «политик памяти» как следствие конкуренции жанров и профилей национальной легитимации как внутри политического пространства России, так и во внешнеполитическом позиционировании российских политических элит. Динамику становления профилей легитимации национальной памяти современной России, можно интерпретировать как эволюцию от «большого» нарратива «новой России» в 1990-е годы к «национальной консолидации» в 2000-е, сопровождаемой высокой амбивалентностью символического кодирования и симбиоза «малых» нарративов, что проявляется в вариативности и конфликтности дискурсов патриотизма.

\section{ЗАКЛЮЧЕНИЕ}

Таким образом, несмотря на значимость современных исследований специфики смысла и содержания российских дискурсов патриотизма в контексте их ценностно-нормативной аксиоматики, растет научная и политическая актуальность разработки междисциплинарных социологических моделей политико-культурной динамики дискурса патриотизма. Анализ социального конструирования политической идентичности, базовых кодексов идентификации национальных элит предполагает выход за рамки трактовки политической идентификации как социокультурной динамики ценностно-нормативных преференций или организационной активности. Успех или неуспех политической идентификации элит предопределяется в значительной степени тем, как происходит процесс становления коммуникативного понимания в пространстве той или иной национальной памяти. При социальном конструировании диалога между национальными элитами важно учитывать различия в понимании ими значимого прошлого, настоящего и будущего, особенностей их коммуникативного «связывания» в символических структурах национальных памятей.

Методологический переход от анализа политической идентичности как производной от социально-экономических и организационных структур к разработке теории и практике коммуникативной автономии символических структур национальной памяти позволяет сконцентрировать внимание на изучении роли пространственно-темпоральных 
структур национальной памяти при оформлении ожиданий политических элит, где специфика (конфигурация) пространственной и временной символизации политических коммуникаций определяет социальное конструирование политических событий, форм солидарности и политической идентификации элит. Эта познавательная установка ориентирует на анализ дискурса патриотизма элитных групп как символических структур («сетей смыслов»), укоренных не только в поведенческих ориентациях представителей политипических элит или их идеологической преференциальности, но и в коммуникативных измерениях структур национальной памяти. В этой теоретической опции политический патриотизм можно определить как сеть солидарных коммуникаций и политических ожиданий, проявляющихся в политической активности граждан национального сообщества, их готовности к ограничению ранее сложившихся ожиданий (вплоть до готовности в экстремальных условиях пожертвовать жизнью) в целях обеспечения существования и развития этого сообщества.

Современная Россия переживает процесс смены профилей легитимации национальной идентичности, обусловленный конфликтной динамикой символических контуров национальной памяти. Исследование символической специфики конкурирующих нарративов гражданственности и его патриотических репрезентаций в национальной памяти современной России в фокусе сравнительного анализа эволюции и социокультурной динамики профилей легитимации национальной памяти, включающих такие взаимосвязанные символические компоненты (образы прошлого и будущего, типологию героического, приоритетные стратегии и практики символического конструирования образа врага и «другого» во внутри- и внешнеполитических коммуникациях) могут стать основой для моделирования процессов развертывания и урегулирования политико-культурных конфликтов, возникающих в процессе реализации политики памяти культурными и политическими элитами.

Специфика эволюции профилей легитимности национальной памяти позволяет выявить высокую степень амбивалентность символического кодирования конкурирующих в национальной памяти России дискурсов патриотизма. Это связано с диверсификацией представлений элитных групп об «учреждающих» («запускающих») событиях в современной политической памяти и радикальным коммуникативным переформатированием символических границ в процессе распада советской политической системы и делегитимацией национальной памяти. Сим- 
волическое оформление травматического нарратива «геополитической катастрофы» распада Советского Союза является «символическим триггером» процессов конкуренции нарративов гражданственности и конфликтного поиска объединяющего нарратива гражданского патриотизма, адекватного социокультурным особенностям эволюции социальной памяти российской цивилизации. «Резонансные истории» антипатриотизма в деятельности современных политических элит и популистские интерпретации элитами политических событий сигнализируют нам об отсутствии содержательных политических нарративов и дискурсов патриотизма, важных для солидарного существования в современном и весьма рискованном политико-культурном многообразии, где продолжает прослеживаться преобладание иерархически индивидуалистических форм элитной консолидации и политической солидарности.

\section{Литература}

Ассман А. Распалась связь времен? Взлет и падение темпорального режима Модерна / пер. с нем. Б. Хлебникова. М.: Новое литературное обозрение. 2017. 267 c.

Бек У. Космополитическое мировоззрение. М.: Центр исследований постиндустриального общества, 2008. 336 с.

Гаман-Голутвина О.В. Политические элиты как объект исследований в отечественной политической науке // Политическая наука. 2016. № 2. С. 38-73.

Дука А.В. Властные элиты в пространстве скандала (случай генерала Золотова) // Власть и элиты / отв. ред. А.В. Дука. Т. 5. СПб.: Интерсоцис, 2018. C. 110-149.

Завершинский К.Ф. Символические измерения социокультурной динамики современных политических элит // Власть и элиты / отв. ред. А. Дука. Т. 5. СПб.: Интерсоцис, 2018. С. 438-460.

Луман Н.Л. Общество как социальная система / пер. с нем. А. Антоновский. М.: Логос, 2004. 232 с.

Мартынов М.Ю., Фадеева Л.А., Габеркорн А.И. Патриотизм как политический дискурс в современной России // Полис. Политические исследования. 2020. № 2. С. 109-121.

Alexander J.C. Cultural pragmatics: social performance between ritual and strategy Social Performance // Symbolic Action, Cultural Pragmatics, and Ritual / ed. by J. C. Alexander, B. Giesen, J. L. Mast. Cambridge: Cambridge University Press, 2006. P. 29-89.

Assmann A. Memory, Individual and Collective // The Oxford Handbook of Contextual Political Analysis / ed. by R.E. Goodin, C. Tilly. New York: Oxford University Press, 2006. P. 210-226. 
Giesen B. Noncontemporaneity, Asynchronicity and Divided Memories // Time \& Society. 2004. Vol. 13, № 1. P. 27-40.

Eisenstaedt N.S., Giesen B. The construction of collective identity // European Journal of Sociology. 1995. Vol. 36, № 1. P. 72-102.

Eisenstadt S.N. The Continual Reconstruction of Multiple Modem Civilizations and Collective Identities // Borderlines in a globalized world. New Perspectives in a Sociology of the World-System / ed. by G. Preyer, M. Bös. Springer-Science+Business Media, B.V., 2002. P. 3-12.

Olick J.K. The Sins of the Fathers: Germany, Memory, Method. Chicago; L.: The University of Chicago Press, 2016. vii+517 p.

Thompson M. Cultural theory as political science // Cultural theory as political science / ed. by M. Thompson, G. Grendstad, P. Selle. L.; N.Y.: Routledge, 2005. P. 1-22.

\title{
“ELITE PATRIOTISM” AS A DISCURSIVE DIMENSION OF THE SYMBOLIC STRUCTURES OF THE NATIONAL MEMORY
}

\author{
K. Zavershinskiy
}

(zavershinskiy200@mail.ru)

St. Petersburg State University,

St. Petersburg, Russia

Citation: Zavershinskiy K. "Patriotizm elit" kak diskursivnoye izmereniye simvolicheskikh struktur natsional'noy pamyati ["Elite patriotism" as a discursive dimension of the symbolic structures of the national memory]. Vlast' $i$ elity [Power and Elites], 2020, 7 (2): 77-96. (In Russian)

DOI: https://doi.org/10.31119/pe.2020.7.2.4

Abstract. The article examines the importance of studying the place and role of the patriotism discourse for the political identification of contemporary elites. The author argues that the dominance of value-normative and positivist research strategies in the study of political communications between elites only partially reflects qualitative changes in the processes of their political identification. According to the author, more promising are the research strategies of contemporary cultural sociology of political phenomena, which allow interpreting the mobility of political identification of elites from the standpoint of the symbolic structures 
dynamics of national memory. The study of the influence in regard to the symbolic structures of national memory on the political identification of elites makes it possible to more adequately delineate the role of the patriotism discourse in the social construction of political solidarity in contemporary national communities. An important role in the study of the political identification of elites is played by the study of the influence attributed to legitimation profiles of national memory on the specifics of their patriotic / non-patriotic identification, which makes it possible to take into account the specifics of the competition between symbolic representations of images of the past and the future, the typology of the heroic, ideas about the guilt and responsibility of elites. Using the theoretical premises of the cultural sociological analysis of contemporary political culture, national memory as a methodological basis, the author proposes a new theoretical approach to the study of the "patriotism of elites" phenomenon.

Keywords: political elites, political communications, national memory, political solidarity, the discourse of patriotism.

\section{References}

Alexander J. C. Cultural pragmatics: social performance between ritual and strategy Social Performance. In: Symbolic Action, Cultural Pragmatics, and Ritual. Ed. by. J. C. Alexander, B. Giesen, J. L. Mast. Cambridge: Cambridge University Press, 2006, pp. 29-89.

Assmann A. Memory, Individual and Collective. In: The Oxford Handbook of Contextual Political Analysis. Ed. by R.E. Goodin, C. Tilly. New York: Oxford University Press, 2006. P. 210-226.

Assman A. Raspalas' svyaz' vremen? Vzlet i padenie temporal'nogo rezhima Moderna [Ist die Zeit aus den Augen? Aufstieg und Fall des Zeitregimes der Moderne]. Moscow: Novoe literaturnoe obozrenie. 2017. 267 p. (In Russian)

Beck U. Kosmopoliticheskoe mirovozzrenie [Cosmopolitan Vision]. Moscow: Centr issledovanij postindustrial'nogo obshchestva, 2008. 336 p. (In Russian)

Duka A.V. Vlastnye elity v prostranstve skandala (sluchaj generala Zolotova) [Power elites in the space of scandal: (case of General Zolotov)]. In: Vlast' i elity [Power and Elites]. Ed. by A.V. Duka. Vol. 5. St. Petersburg: Intersotsis, 2018, pp. 110-149. (In Russian)

Eisenstaedt N.S., Giesen B. The construction of collective identity, European Journal of Sociology, 1995, 36 (1), pp. 72-102.

Eisenstadt S.N. The Continual Reconstruction of Multiple Modem Civilizations and Collective Identities. In: Borderlines in a globalized world. New Perspectives in a Sociology of the World-System. Ed. by G. Preyer, M. Bös. Springer-Science+Business Media, B.V., 2002, pp. 3-12.

Gaman-Golutvina O.V. Politicheskie elity kak obyekt issledovanij v otechestvennoj politicheskoj nauke [Political elites as an object of research in Russian political science], Politicheskaya nauka [Political Science], 2016, 2, pp. 38-73. (In Russian) 
Giesen B. Noncontemporaneity, Asynchronicity and Divided Memories, Time \& Society, 2004, 13 (1), pp. 27-40.

Luman N.L. Obshchestvo kak social'naya sistema [Society as a Social System]. Moscow: Logos, 2004. 232 p. (In Russian)

Martynov M.Yu., Fadeeva L.A., Gaberkorn A.I. Patriotizm kak politicheskij diskurs v sovremennoj Rossii [Patriotism as a political discourse in modern Russia]. Polis. Politicheskie issledovaniya [Polis. Political Studies], 2020, 2, pp. 109-121. (In Russian)

Olick J. K. The Sins of the Fathers: Germany, Memory, Method. Chicago; London: The University of Chicago Press, 2016. vii+517 p.

Thompson M. Cultural theory as political science. In: Cultural theory as political science. Ed. by M. Thompson, G. Grendstad, P. Selle. London; New York: Routledge, 2005, pp. 1-22.

Zavershinskij K.F. Simvolicheskie izmereniya sociokul'turnoj dinamiki sovremennyh politicheskih elit [Symbolic dimensions of socio-cultural dynamics of contemporary political elites]. In: Vlast' i elity [Power and Elites]. Ed. by A.V. Duka. Vol. 5. St. Petersburg: Intersotsis, 2018, pp. 438-460. (In Russian) 